\title{
ENCAPSULAÇÃO DE ÓLEO ESSENCIAL DE TOMILHO PARA AUMENTO DA ATIVIDADE ANTIMICROBIANA
}

\section{Nathalia Dias Goncalves1; Ana Silvia Prata1; Marta Cristina Teixieira Duarte2;}

Adilson Sartorato2 ; Camila Derlamelina2 (ndg_nathydias@ hotmail.com)

1 Faculdade de Engenharia de Alimentos - Universidade Estadual de Campinas (UNICAMP), Brasil.

2 Centro Pluridisciplinar de Pesquisas Químicas, Biológicas e Agrícolas - Universidade Estadual de Campinas (UNICAMP), Brasil.

Para evitar a contaminação microbiológica de produtos alimentícios, a indústria de alimentos faz uso de conservantes, geralmente de natureza sintética, capazes de fornecer alto grau de proteção contra micro-organismos patogênicos e aumentar a vida de prateleira do produto. No entanto o consumidor tem priorizado produtos livre de aditivos sintéticos com apelo a saudabilidade. A ação antimicrobiana do óleo essencial de tomilho (OET) deve-se à combinação de seus componentes fenólicos (timol e carvacrol). A alta volatilidade, destes compostos é um desafio para aplicação em alimentos. O uso da microencapsulação permite a formação de uma barreira física que pode proteger o composto encapsulado das condições do meio. O objetivo desde trabalho foi microencapsular o OET através da técnica de coacervação complexa afim de aumentar a sua propriedade antimicrobiana. Para formação das micropartículas foi preparada uma solução de gelatina tipo B $(2,5 \%)$ a $50{ }^{\circ} \mathrm{C}$ que foi homogeneizada com o OET $(2,5 \mathrm{~g})$ num Ultra Turrax a $14.000 \mathrm{rpm}$ (3 min), posteriormente uma solução de goma arábica $(2,5 \%)$ a $50{ }^{\circ} \mathrm{C}$ foi adicionada e o $\mathrm{pH}$ ajustado para 4 . O sistema foi mantido em agitação magnética durante todo o processo e arrefecido a $10{ }^{\circ} \mathrm{C}(30 \mathrm{~min})$. As micropartículas foram armazenadas em geladeira a $10{ }^{\circ} \mathrm{C} / 16 \mathrm{~h}$. Após esse processo foi realizada a reticulação com tripolifosfato de sódio, $(3 \%, \mathrm{p} / \mathrm{p})$ adicionado a $0,07 \mathrm{~g}$ por grama de polímero. A morfologia das micropartículas foi observada com microscopio confocal. A determinação da atividade antimicrobiana foi avaliada pelo método de microdiluição para bactérias Gram positivas e Gram negativas (E. faecium, E. hirae, E. coli, S. choleraesuis, S. tiphymurium, S. aureus). O OET livre e o encapsulado foram dispersos em meio Müeller - Hinton com 2,5\% dimetilsulfóxido e solução de Tween 80 em água $(0,1 \%)$. Os valores de Concentração Inibitória Mínima (MIC) para o óleo encapsulado foi inferior cerca de dez vezes, comparado com a efetividade do óleo livre. Fica comprovado que as propriedades antimicrobianas do OET foram potencializadas quando contido nas micropatículas. Valores de MIC foram registrados entre 0,010 e $0,030 \mathrm{mg} / \mathrm{ml}$ sendo que a quantidade de óleo presente dentro da partícula necessária para inibição de cada micro-organismo testado foi definida através do cálculo de acordo com o valor de liberação (load úmido = 0,06 g). Outras investigações nesse sistema e o seu impacto de preservação em outras culturas são sugeridas.

Palavras-chave: bactérias; conservantes naturais de alimentos; deterioração de alimentos. 